\section{What's New in Building Energy
Research}
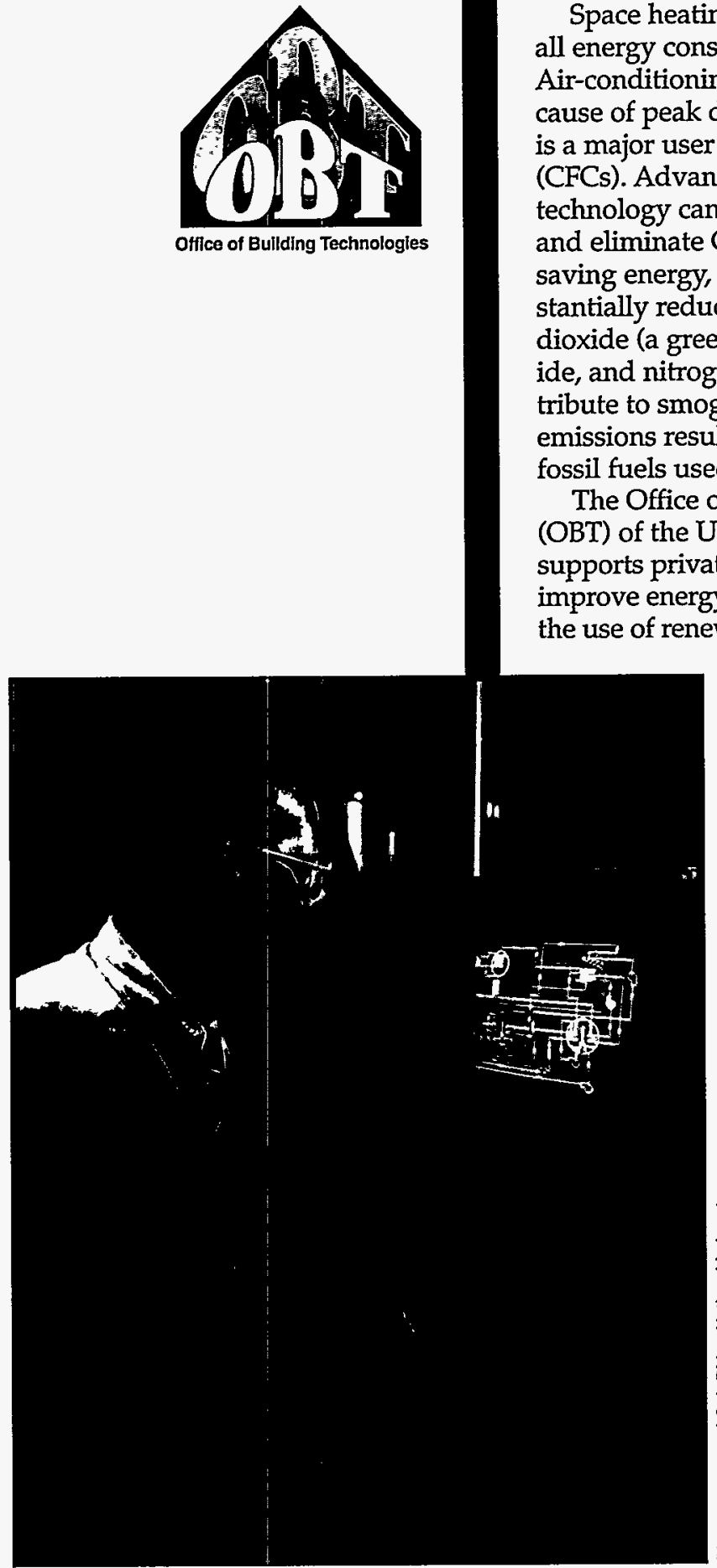

Oak Ridge scientist performs cycle analysis using an absorber simulation tool.

\title{
Thermally Activated Heat Pumps
}

\author{
Efficient gas-fired heat pumps heat and cool \\ buildings without CFCs
}

Space heating and cooling use $46 \%$ of all energy consumed in U.S. buildings. Air-conditioning is the single leading cause of peak demand for electricity and is a major user of chlorofluorocarbons (CFCs). Advanced energy conversion technology can save $50 \%$ of this energy and eliminate CFCs completely. Besides saving energy, advanced systems substantially reduce emissions of carbon dioxide (a greenhouse gas), sulfur dioxide, and nitrogen oxides, which contribute to smog and acid rain. These emissions result from the burning of fossil fuels used to generate electricity.

The Office of Building Technologies (OBT) of the U.S. Department of Energy supports private industry's efforts to improve energy efficiency and increase the use of renewable energy in buildings. To help industry, OBT, through the Oak Ridge National Laboratory, is currently working on thermally activated heat pumps. OBT has selected the following absorption heat pump systems to develop:

- Generatorabsorber heatexchange (GAX) cycle for heatingdominated applications in residential and light commercial buildings

- Double-condensercoupled (DCC) cycle for commercial buildings.
In addition, OBT is developing computer-aided design software for investigating the absorption cycle.

\section{Heat Pump Technology}

Heat pumps in use today are electrically driven, operating on the conventional vapor-compression refrigeration cycle, taking heat at a lower temperature and releasing it at a higher temperature. A reversing valve allows the heat pump to provide space heating or cooling as necessary.

A major advantage of the heat pump over conventional furnaces is that it can deliver more than one unit of output energy per unit of input energy. In other words, its coefficient of performance (COP) is greater than 1. The COP for the best combustion heating processes is only about 0.95 because of thermodynamic losses. In addition, the heat pump can be driven directly by thermal energy from natural gas. This avoids the substantial energy conversion losses (approximately 70\%) associated with electric power generation and distribution.

\section{Absorption Heat Pumps}

An absorption heat pump is driven by boiling an environmentally benign refrigerant solution in a generator (or desorber) chamber. The high-pressure vapor condenses to a liquid while giving up heat in a condenser. The liquid then passes through a pressure-reducing valve and evaporates by absorbing heat in an evaporator. Finally, the vapor is reabsorbed into the solution in an absorber chamber. The driving energy comes from the thermal energy used for boiling, plus a small amount of electricity for pumping the solution from the absorber back to the generator. 
In the heating mode, heat is taken from outside air when the refrigerant evaporates and delivered to the building interior when it condenses. In the cooling mode, the function of the two heat-exchanger coils is reversed, so heat moves from inside to outside.

Absorption heat pumps can double the efficiency of natural gas heating (to give a heating COP of 1.6 to 2.1). They can also reduce the impact of electric peak loads in cooling by the more efficient use of natural gas (with a cooling COP of 0.8 to 1.4 ).

\section{The GAX Cycle}

The GAX cycle was first patented in 1913 but not put into practice until the early 1980s. The GAX heat pump uses an ammonia-water solution in an absorption cycle. An energy-recovery heat-exchange loop between the generator and absorber raises the thermal efficiency by recovering the exothermic heat energy released when the ammonia refrigerant mixes with water in the absorber. A natural gas burner supplies heat to the generator.

Based on successful testing of proofof-principle prototypes and on independent manufacturing-cost and market-potential studies, development work is being completed. OBT efforts are turning to demonstrating and commercializing the first-generation GAX heat pump.

Carrier Corporation, the world's largest manufacturer of heating, ventilating, and air-conditioning equipment, has licensed the technology from Phillips Engineering, the developing company. A partnership with the Gas Research Institute, gas utilities, and the American Gas Cooling Center increases the likelihood of successful early market entry, which is scheduled for 1997.

\section{Commercial Chiller}

Progress in advanced-cycle absorption chillers is bringing new interest to this technology, which was once commonly used in U.S. commercial buildings. It rapidly lost market share to electrically driven vapor compression systems. OBT's effort is aimed at developing a chiller of more than 100 tons capacity with a COP of 1.4 to 1.6 .

The system is based on a DCC cycle invented under the OBT program and patented in April 1993. A triple-effect system, it operates at a higher temperature than conventional chillers do. It uses a standard refrigerant solution of lithium bromide in water but with fluid additives to mitigate material corrosion.

Battelle Laboratories is testing critical components, and York International is fabricating a full-scale unit. Additional research is being conducted on hightemperature absorber additives and advanced absorption fluids. A natural gas industry consortium will evaluate and assist in commercializing the DCC chiller.

\section{Computer-Aided Design}

To give designers of absorption systems the same level of design tools available for electric heat pumps, OBT is developing modular computer software for simulating and optimizing the absorption cycle. A first-generation model, called ABSIM, has been used to evaluate advanced-cycle absorption equipment and is now being transferred to industry.

\section{Maintaining Leadership in World Markets}

Oak Ridge has been leading the effort on developing thermally activated heat pumps since 1978. Oak Ridge works closely with other research institutions, utilities, equipment manufacturers, and design professionals.

Competition is intense in the global marketplace for space-conditioning equipment. To maintain U.S. technical leadership, OBT has initiated costshared research and development on

\section{Progress in Absorption Heat Pump Efficiency}

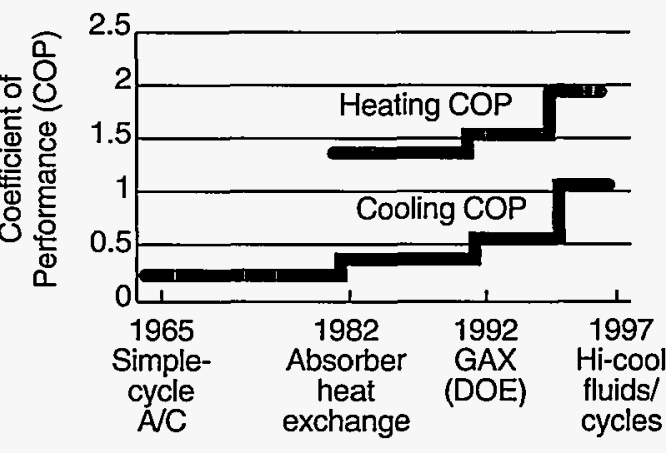

second-generation absorption heat pumps using both advanced cycles and advanced working fluids and materials. For example, Oak Ridge is developing ammonia-based quaternary fluids for use in advanced systems.

These technical developments will be integrated into an advanced-cycle HI-COOL absorption heat pump with a cooling performance at least $30 \%$ better than that of the GAX heat pump. This advanced system is intended for small commercial buildings nationwide and residential buildings in the south, where cooling loads are high.

\section{For More Information}

Ronald Fiskum

Program Manager

Office of Building Technologies, EE-422

U.S. Department of Energy

1000 Independence Avenue, SW

Washington, DC 20585

(202) $586-9130$

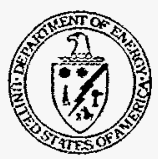

Produced for DOE's Office of Energy Efficiency and Renewable Energy by the National Renewable Energy Laboratory, a DOE national laboratory

DOE/GO-10095-087

DE95004009

May 1995

Printed with a biodegradable ink on paper containing at least $50 \%$ wastepaper including $20 \%$ postconsumer waste 


\section{DISCLAIMER}

This report was prepared as an account of work sponsored by an agency of the United States Government. Neither the United States Government nor any agency thereof, nor any of their employees, make any warranty, express or implied, or assumes any legal liability or responsibility for the accuracy, completeness, or usefulness of any information, apparatus, product, or process disclosed, or represents that its use would not infringe privately owned rights. Reference herein to any specific commercial product, process, or service by trade name, trademark, manufacturer, or otherwise does not necessarily constitute or imply its endorsement, recommendation, or favoring by the United States Government or any agency thereof. The views and opinions of authors expressed herein do not necessarily state or reflect those of the United States Government or any agency thereof. 


\section{DISCLAIMER}

Portions of this document may be illegible in electronic image products. Images are produced from the best available original document. 